\title{
Mathematical Modeling of Fluid Flow, Heat Transfer, and Solidification in Two-roll Melt Drag Thin Strip Casting of Steel
}

\author{
Manish GUPTA and Yogeshwar SAHAI \\ Department of Materials Science and Engineering, The Ohio State University, Columbus OH 43210 USA. \\ E-mail: Sahai.1@osu.edu
}

(Received on July 27, 1999; accepted in final form on September 30, 1999)

\begin{abstract}
A two-dimensional finite element model has been developed to simulate fluid flow, heat transfer, and solidification in two-roll melt drag thin strip casting of steel. The two equation $k-\varepsilon$ model is used to incorporate the turbulence in fluid flow. The effect of solidification of liquid metal on the viscosity of melt is also considered. The release of latent heat of fusion at the solid-liquid interface was not considered explicitly, but the specific heat was increased appropriately to account for the released latent heat. The roller velocity, melt-roll heat transfer coefficient and melt superheat are identified as important process variables, and their effect on the thickness of cast strip is predicted.
\end{abstract}

KEY WORDS: two-roll melt drag thin strip casting; heat transfer; fluid flow; turbulence; solidification.

\section{Introduction}

Thin strip casting process to cast molten metal directly into thin strips has many advantages over conventional continuous and ingot casting methods, like reduced energy consumption, improved process efficiency and better mechanical properties. The important thin strip casting processes are:

(1) Melt drag process

(2) Twin roller casting process

(3) Two-roller melt drag process

The advantages of strip casting processes have drawn the attention of researchers in the recent years. Gupta and Sahai ${ }^{1)}$ have done a significant amount of work in mathematical modeling of these strip casting processes. In their previous works, they simulated melt drag, twin roll, and two-roll melt drag thin strip casting processes. The mathematical model developed by them simulated the coupled turbulent flow, heat transfer, and solidification of liquid steel in the melt pool. Their results for melt drag and twin roll casting methods matched well with the pilot plant data. In the case of two roll melt drag method, the design of caster in previous work by Gupta and Sahai ${ }^{1)}$ was such that the 'kissing point' (which is the point of least separation of two rolls) of rolls lied above the molten metal level in the melt pool. This is undesirable for smooth flow of liquid metal in the melt pool because then the rolls have to pull the metal against the gravitational force.

In present work, design of the caster was modified to make both the rolls of equal diameter. The rolls were oriented such that the kissing point of two rolls lies below the liquid metal level in the melt pool. The geometry of this model is shown in Fig. 1.

As done in earlier works by Gupta and Sahai, ${ }^{1)}$ finite ele- ment mesh was generated in the calculation domain and a two dimensional mathematical model was developed to simulate turbulent fluid flow, heat transfer and solidification. A commercially available finite element code, FIDAP was used for this simulation. The two equation $k-\varepsilon$ model was used for turbulence considerations. Process variables which affect the cast strip thickness were identified as roller velocity, melt-roll heat transfer coefficient, and melt super heat. Strip thickness as a function of these variables was also predicted in this work.

\section{Geometry of the Model and Calculation Domain}

Figure 1 shows the computational domain for the mathematical model. The computational domain included both

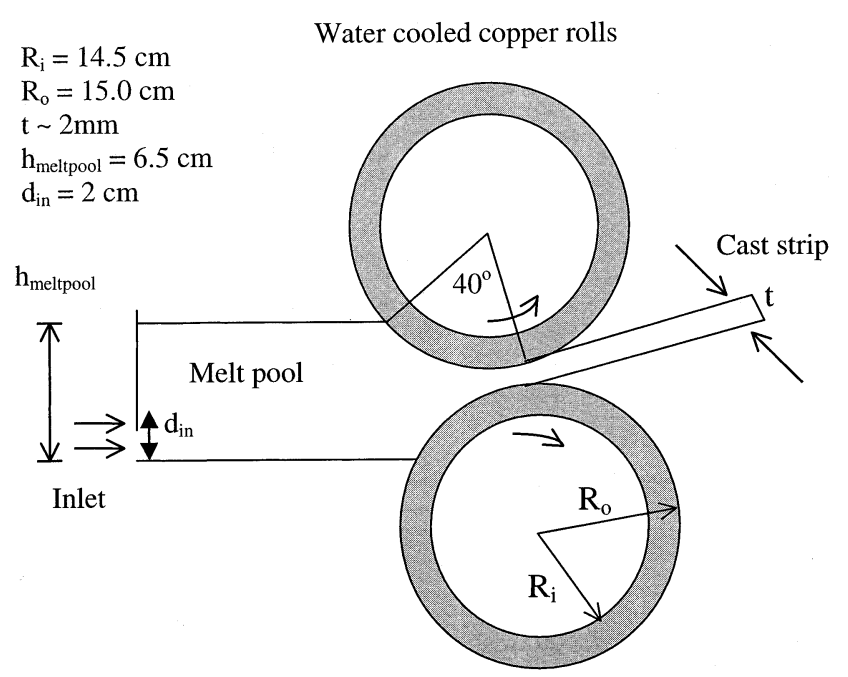

Fig. 1. Schematic of the caster and computational domain. 
rollers, melt pool and part of the solidified strip. The geometry of the model is such that both rollers are of same diameter $(300 \mathrm{~mm})$. Angle of contact of rollers with melt pool is $40^{\circ}$. Rolls are oriented at an inclination of $10^{\circ}$ with the vertical. This orientation of rolls insures that the kissing point of rollers lies below the molten metal level in the melt pool, and the melt/roll contact length is same for both the rolls.

\section{Mathematical Model}

A two-dimensional finite element model was developed to simulate the turbulent fluid flow, heat transfer, and solidification in this process. Following assumptions were made in the development of the mathematical model.

\subsection{Assumptions}

The assumptions made in the development of the mathematical model for two roll melt drag process are as follows:

1) The process is at steady state. After a small initial transient period, process parameters do not change with time.

2) By taking into account the fact that width/thickness ratio is very large and ignoring the end effects, the geometry of the process can be approximated as twodimensional.

3) Liquid steel is incompressible and is a Newtonian fluid.

4) Material properties (except viscosity and specific heat) are temperature independent.

5) There is no segregation.

6) Temperature may be used as the criterion for determination of the strip thickness.

7) There is a no slip condition between the wheel and the solidified strip.

8) Heat losses by radiation are negligible.

9) Roller surface is perfectly clean.

10) Process is assumed to be growth controlled.

11) There is no entrainment of gas.

\subsection{Transport Equations}

Under the above assumptions, following transport equations were solved in the calculation domain:

(i) Continuity equation:

The continuity equation, which is conservation of mass, can be expressed in following two-dimensional form,

$$
\frac{\partial U}{\partial x}+\frac{\partial V}{\partial y}=0
$$

(ii) Turbulent Navier-Stokes equation:

The Navier-Stokes equation, which is a momentum balance equation, can be expressed, for a steady state, two-dimensional incompressible fluid flow, in the following form,

$$
\begin{aligned}
\left(U \frac{\partial U}{\partial x}+V \frac{\partial U}{\partial y}\right) \rho= & -\frac{\partial P}{\partial x}+\rho f_{x}+2 \frac{\partial}{\partial x}\left(\mu_{\mathrm{eff}} \frac{\partial U}{\partial x}\right) \\
& +\frac{\partial}{\partial y}\left(\mu_{\mathrm{eff}}\left(\frac{\partial U}{\partial y}+\frac{\partial V}{\partial x}\right)\right) \ldots \ldots . . . . .
\end{aligned}
$$

$$
\begin{aligned}
\left(U \frac{\partial V}{\partial x}+V \frac{\partial V}{\partial y}\right) \rho= & -\frac{\partial P}{\partial y}+\rho f_{y}+2 \frac{\partial}{\partial y}\left(\mu_{\mathrm{eff}} \frac{\partial V}{\partial y}\right) \\
& +\frac{\partial}{\partial x}\left(\mu_{\mathrm{eff}}\left(\frac{\partial U}{\partial y}+\frac{\partial V}{\partial x}\right)\right) \ldots \ldots . . .
\end{aligned}
$$

(iii) Equation for conservation of thermal energy: Conservation of thermal energy can be written as,

$$
\begin{aligned}
\left(U \frac{\partial T}{\partial x}+V \frac{\partial T}{\partial y}\right) \rho c_{\mathrm{p}}= & \frac{\partial}{\partial x}\left(K_{\text {eff }} \frac{\partial T}{\partial x}\right) \\
& +\frac{\partial}{\partial y}\left(K_{\text {eff }} \frac{\partial T}{\partial y}\right)+H
\end{aligned}
$$

where $H$ is the heat generation term.

\subsection{Turbulence Model}

The two equation $k-\varepsilon$ model of turbulence of Launder and Spalding ${ }^{2)}$ was used for the turbulence considerations. Governing transport equations for turbulent kinetic energy, $k$ and its dissipation rate, $\varepsilon$ can be written as follows.

Turbulent kinetic energy equation.

$$
\begin{aligned}
\left(U \frac{\partial k}{\partial x}+V \frac{\partial k}{\partial y}\right) \rho= & -\rho \varepsilon+\mu_{\mathrm{t}} \varphi \\
& +\frac{\partial}{\partial x}\left(\frac{\mu_{\mathrm{t}}}{\sigma_{k}} \frac{\partial k}{\partial x}\right)+\frac{\partial}{\partial y}\left(\frac{\mu_{\mathrm{t}}}{\sigma_{k}} \frac{\partial k}{\partial y}\right)
\end{aligned}
$$

Dissipation rate of turbulence equation.

$$
\begin{aligned}
\left(U \frac{\partial \varepsilon}{\partial x}+V \frac{\partial \varepsilon}{\partial y}\right) \rho= & -C_{2} \rho \frac{\varepsilon^{2}}{k}+C_{1} \mu_{\mathrm{t}} \varphi \frac{\varepsilon}{k} \\
& +\frac{\partial}{\partial x}\left(\frac{\mu_{\mathrm{t}}}{\sigma_{\varepsilon}} \frac{\partial \varepsilon}{\partial x}\right)+\frac{\partial}{\partial y}\left(\frac{\mu_{\mathrm{t}}}{\sigma_{\varepsilon}} \frac{\partial \varepsilon}{\partial y}\right)
\end{aligned}
$$

Where,

$$
\begin{gathered}
\mu_{\text {eff }}=\mu_{\mathrm{o}}+\mu_{\mathrm{t}} \\
\mu_{\mathrm{t}}=C_{\mu} \rho k^{2} / \varepsilon \\
K_{\mathrm{eff}}=K_{\mathrm{o}}+K_{\mathrm{t}} \\
K_{\mathrm{t}}=c_{\mathrm{p}} \mu_{\mathrm{t}} / \operatorname{Pr} .
\end{gathered}
$$

Where, Pr is the turbulent Prandtl number. In the present simulation, a value of 1 is taken for Pr.

$\varphi$ in Eqs. (5) and (6) is given by the following expression.

$$
\varphi=2\left(\frac{\partial U}{\partial x}\right)^{2}+2\left(\frac{\partial V}{\partial y}\right)^{2}+\left(\frac{\partial V}{\partial x}+\frac{\partial U}{\partial y}\right)^{2}
$$

According to Launder and Spalding, ${ }^{2)}$ the five constants appearing in Eqs. (5) and (6) take the following values.

$$
C_{1}=1.44, \quad C_{2}=1.92, \quad C_{\mu}=0.09, \quad \sigma_{\mathrm{k}}=1.0, \quad \sigma_{\varepsilon}=1.3
$$

\subsection{Effective Viscosity Model}

The effective viscosity of the liquid metal will be the sum of turbulent and laminar viscosity. In the solid phase, the viscosity is very high and hence the flow can be considered as laminar. A model was used to reduce turbulent vis- 


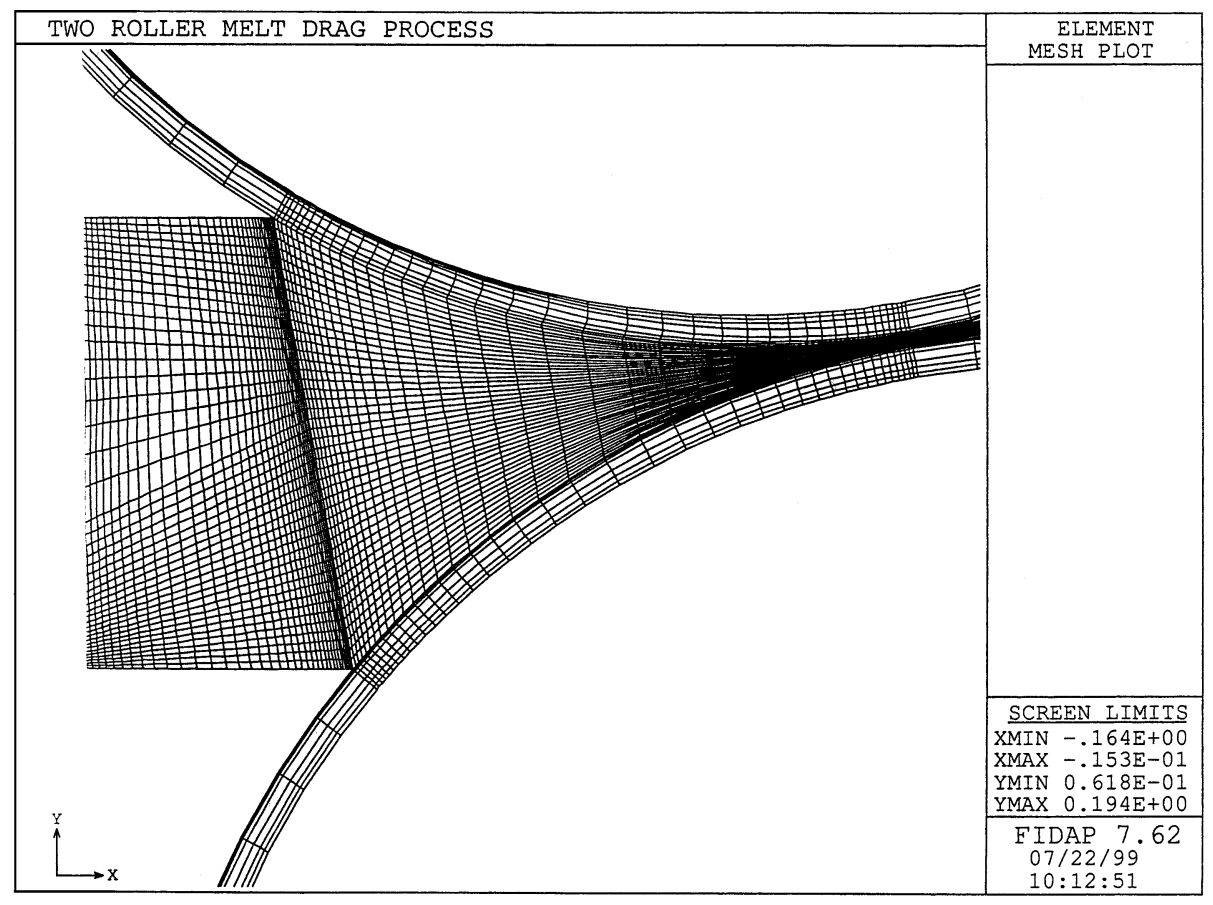

Fig. 2. The finite element mesh used in the present simulation.

cosity to zero in the solid phase, i.e. decay it to zero in some transition zone. ${ }^{3)}$

$$
\begin{aligned}
& \mu_{\mathrm{t}} \equiv \mu_{\mathrm{t}}^{*} f_{\text {decay }} \\
& f_{\text {decay }}=\lambda^{1.5} \exp \left[-3.4 /\left(1+R_{\mathrm{t}} / 50\right)^{2}\right] \\
& R_{\mathrm{t}}=\rho k^{2} /\left(\mu_{\mathrm{o}} \varepsilon\right) \text {. } \\
& \lambda=\left[\left(T-T_{\text {liq }}\right) /\left(T_{\text {sol }}-T_{\text {liq }}\right)\right]^{\text {power }}
\end{aligned}
$$

Value of 'power' can be set for the desired slope of viscosity in the transition zone to represent the mushy zone. In the present simulation 'power' is taken as one, which represents a linear variation of fraction of solid with temperature.

\subsection{Boundary Conditions}

The governing equations were subject to boundary conditions on every surface of the computational domain. These boundary conditions are,

Inlet

Horizontal component of velocity: $\quad U=U_{\text {in }}$.

Vertical component of velocity: $V=0$.

$$
T_{\text {in }}=T_{\text {liq }}+T_{\text {sup }}, \quad k=a \cdot U_{\text {in }}^{2}
$$

A value of 0.01 was used for ' $a$ ' in the present work.

$\varepsilon=k^{1.5} \cdot 10 / \delta$, where $\delta$ is the characteristic thickness of shear width. $\delta$ is taken as the size of the inlet.

\section{Refractory Walls of Tundish}

At all refractory walls the zero slip condition was applied. All refractory walls were assumed to be thermally insulated. Kinetic energy and dissipation were also specified to be zero at the wall.

$U_{\text {wall }}=0, \quad V_{\text {wall }}=0, \quad$ Heat flux $x_{\text {wall }}=0, \quad k_{\text {wall }}=0, \quad \varepsilon_{\text {wall }}=0$.

Outer Surface of the Rolls

Tangential and normal velocities were specified on this surface.

$$
U_{\mathrm{t}}=V_{\text {cast }}, \quad U_{\mathrm{n}}=0 .
$$

An effective heat transfer coefficient due to convective and radiative heat transfer to the atmosphere from this surface was specified as $50 \mathrm{~W} / \mathrm{m}^{2} \mathrm{~K}^{1)}$ and reference temperature was specified as $300 \mathrm{~K}$.

Inner Surface of the Rolls

At the inner surface of the rolls, normal velocity was specified as zero and the tangential velocity was calculated using casting velocity.

$$
U_{\mathrm{t}}=V_{\text {cast }} \cdot R_{\mathrm{i}} / R_{\mathrm{O}}, \quad U_{\mathrm{n}}=0 .
$$

Convective heat transfer coefficient was specified as $10 \mathrm{~kW} / \mathrm{m}^{2} \mathrm{~K}^{1)}$ and reference temperature was specified as $313 \mathrm{~K}$.

\section{Strip/Roll Interface}

The heat transfer coefficient to represent the heat transfer from melt pool to the rollers is found to vary over a wide range of values as reported in the literature. ${ }^{4-8)}$ In the present work, the value of this heat transfer coefficient was taken as $11 \mathrm{~kW} / \mathrm{m}^{2} \mathrm{~K}$.

\subsection{Solution Methodology}

A finite element mesh using about 6000 nodes was generated. This finite element mesh is shown in Fig. 2. The transport equations described above were converted into algebraic equations by using a finite element method, assembled and solved simultaneously by a general purpose finite element method, commercial code FIDAP. ${ }^{3)}$ The governing equations in this model are highly non-linear and coupled. The solution of these equations, in a turbulent, recirculatory flow field with steep viscosity change and continuous release of latent heat in bulk, becomes highly unstable. In present simulation, successive substitution technique was 
Table 1. Thermo-physical values used in the mathematical model.

$\begin{array}{lc}\text { Latent heat of fusion of steel } & 272000 \mathrm{~J} / \mathrm{kg} \\ \text { Thermal conductivity of solidified steel } & 28 \mathrm{~W} / \mathrm{m} \mathrm{K} \\ \text { Density of solidified steel } & 7200 \mathrm{~kg} / \mathrm{m}^{3} \\ \text { Degree of superheat in steel } & 60 \mathrm{~K} \\ \text { Atmosphere temperature } & 300 \mathrm{~K} \\ \text { Cooling water temperature } & 313 \mathrm{~K} \\ \text { Thermal conductivity of copper } & 390 \mathrm{~W} / \mathrm{m} \mathrm{K} \\ \text { Thickness of both the rollers } & 5 \mathrm{~mm} \\ \text { Melt-roll heat transfer coefficient } & 11.0 \mathrm{~kW} / \mathrm{m}^{2} \mathrm{~K} \\ \text { Heat transfer coefficient for cooling fluid } & 10 \mathrm{~kW} / \mathrm{m}^{2} \mathrm{~K} \\ \text { Roller diameter } & 300 \mathrm{~mm} \\ \text { Contact angle } & 40^{\circ} \\ \text { Liquidus temperature of steel } & 1733 \mathrm{~K} \\ \text { Solidus temperature of steel } & 1673 \mathrm{~K} \\ \text { Roller material } & \text { Copper }\end{array}$

used to solve these equations. Successive substitution method using an under relaxation factor of 0.5 was found to give converged solution. Details of this method can be found in reference 3 .

\subsection{Material Properties}

The temperature independent thermo-physical property values and other parameters used for the present simulation are given in Table 1.

In this model, viscosity was modeled as a function of temperature with liquid viscosity of $0.005 \mathrm{~Pa} \cdot \mathrm{s}$ at liquidus and very high viscosity $\left(10^{5} \mathrm{~Pa} \cdot \mathrm{s}\right)$ at solidus. Figure 3 shows the temperature dependence of viscosity.

The release of latent heat of fusion at the solid/liquid interface was not considered explicitly, but the specific heat was increased appropriately to account for the released latent heat. An enthalpy based approach was used to evaluate the specific heat for this model. In this approach the specif-

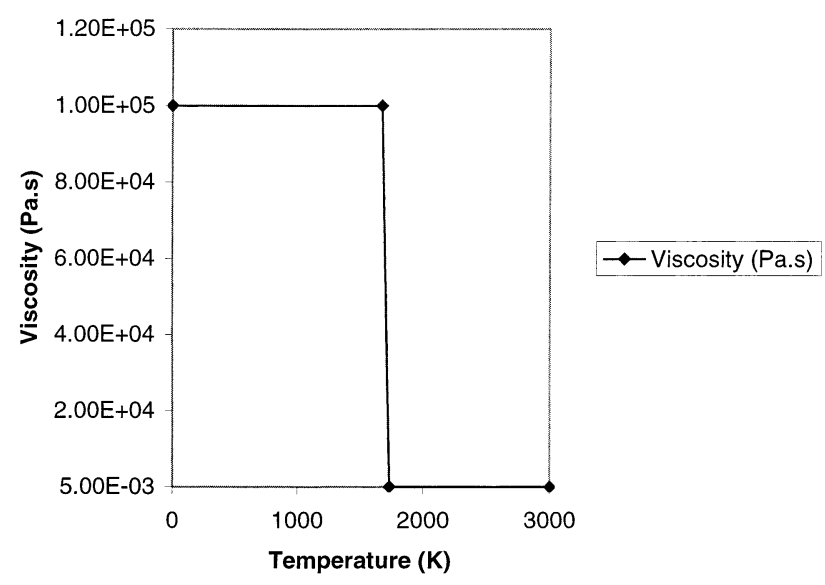

Fig. 3. Viscosity $(\mathrm{Pa} \cdot \mathrm{s})$ of the liquid steel as a function of the temperature $(\mathrm{K})$.

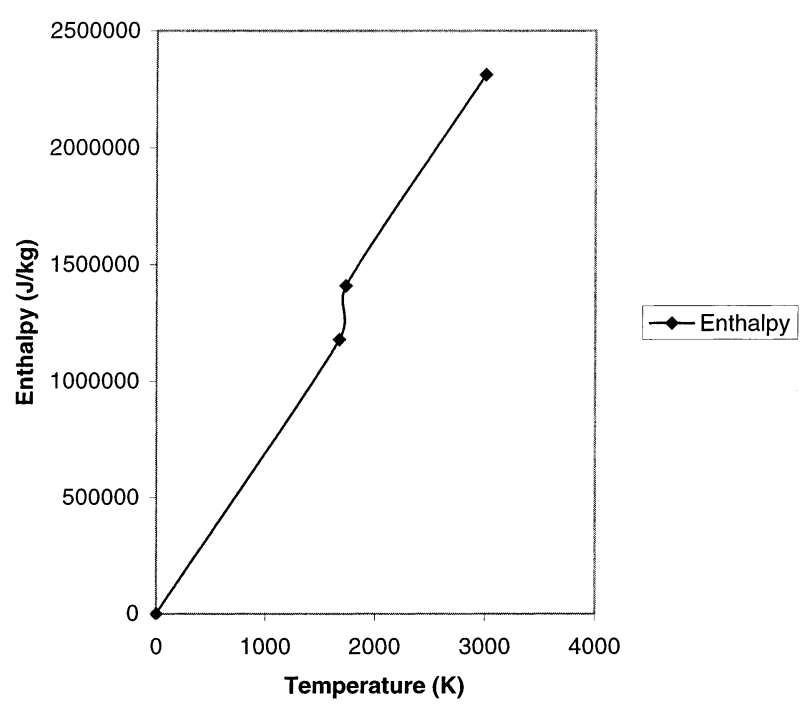

Fig. 4. The enhalpy-temperature curve for liquid steel.

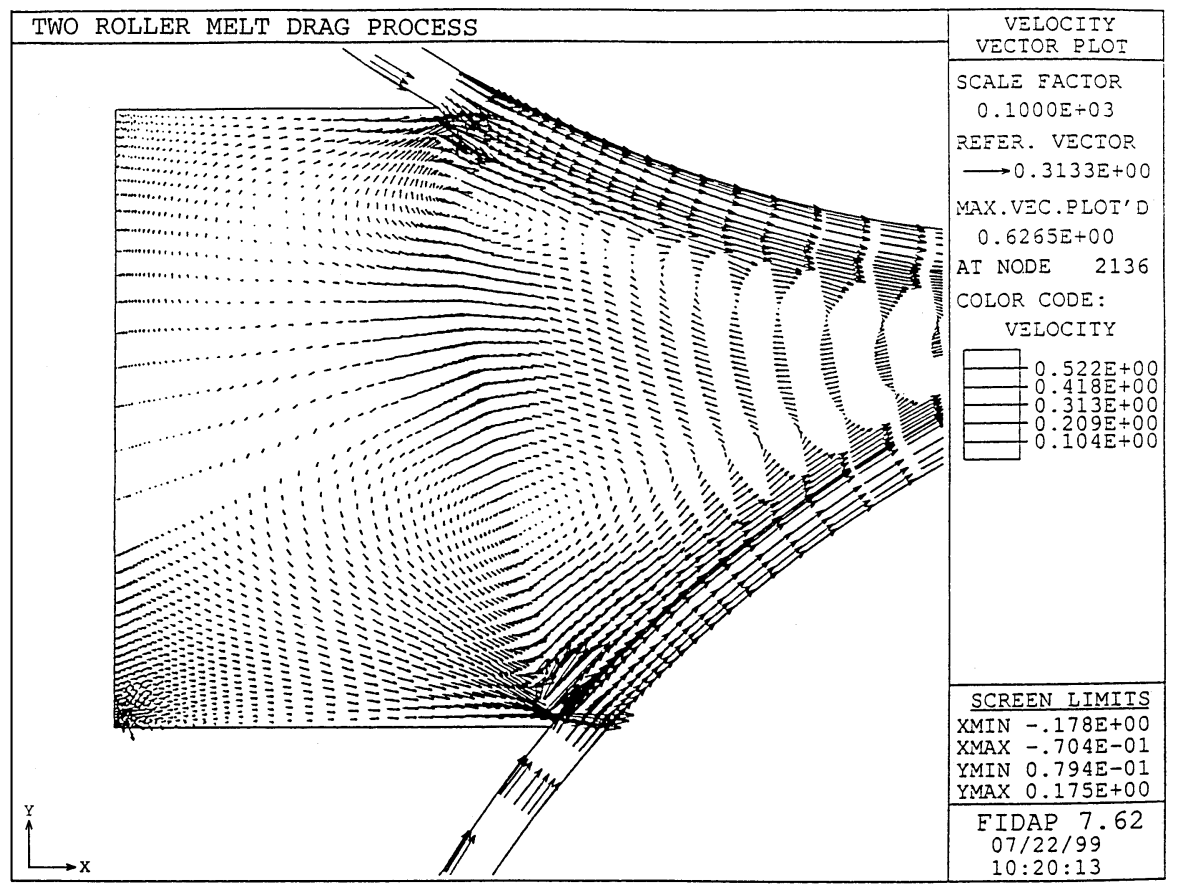

Fig. 5. Velocity $(\mathrm{m} / \mathrm{s})$ vectors in the melt pool and rolls for two-roll melt drag thin strip casting of steel $\left(T_{\text {sup }}=60 \mathrm{~K}\right.$, $V_{\text {roll }}=0.77 \mathrm{~m} / \mathrm{s}, U_{\text {in }}=0.05 \mathrm{~m} / \mathrm{s}, h_{\text {melt-roll }}=11000 \mathrm{~W} / \mathrm{m}^{2} \mathrm{~K}$ ). 


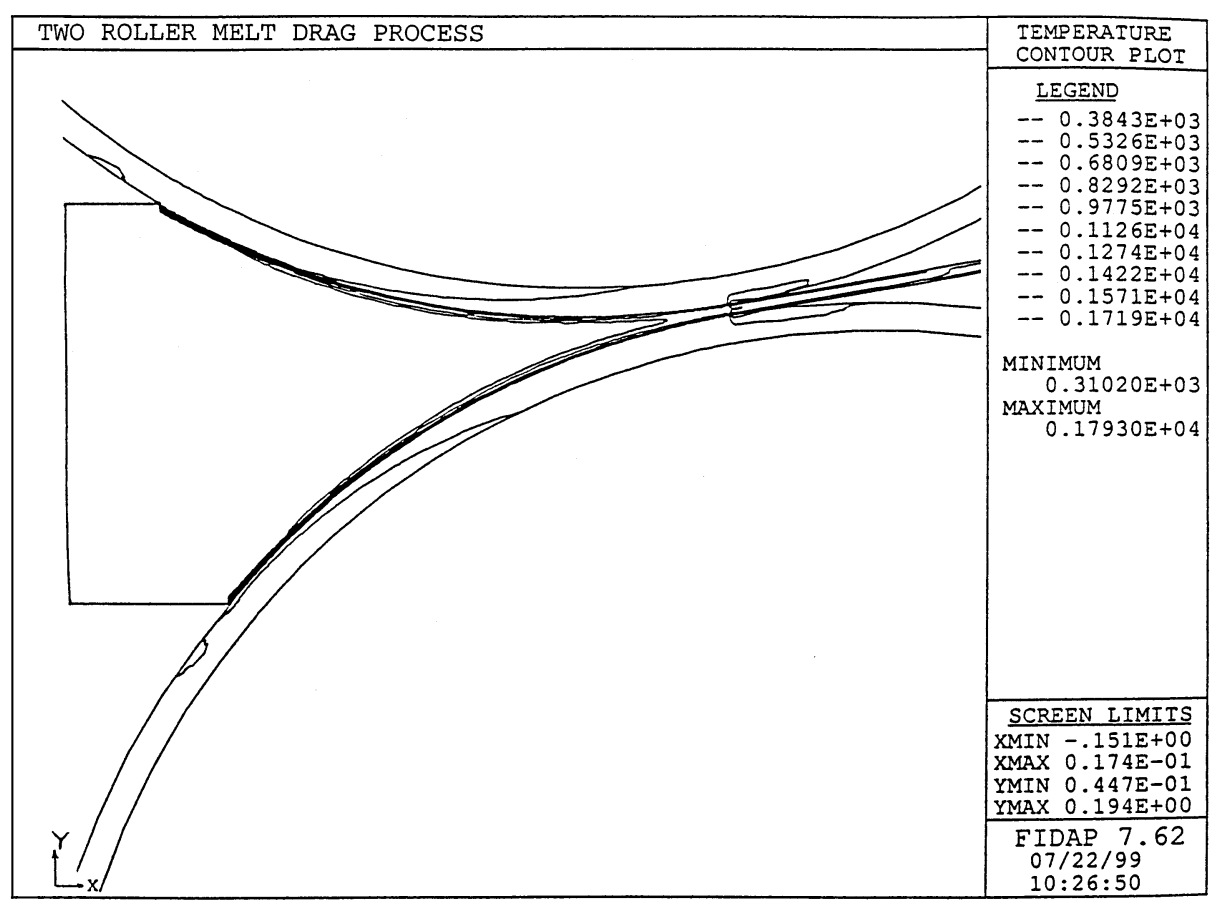

Fig. 6. Temperatures $(\mathrm{K})$ contours in the melt pool and the rolls for two-roll melt drag thin strip casting of steel ( $T_{\text {sup }}=60 \mathrm{~K}, V_{\text {roll }}=0.77 \mathrm{~m} / \mathrm{s}, U_{\text {in }}=0.05 \mathrm{~m} / \mathrm{s}, h_{\text {melt-roll }}=11000 \mathrm{~W} / \mathrm{m}^{2} \mathrm{~K}$ ).

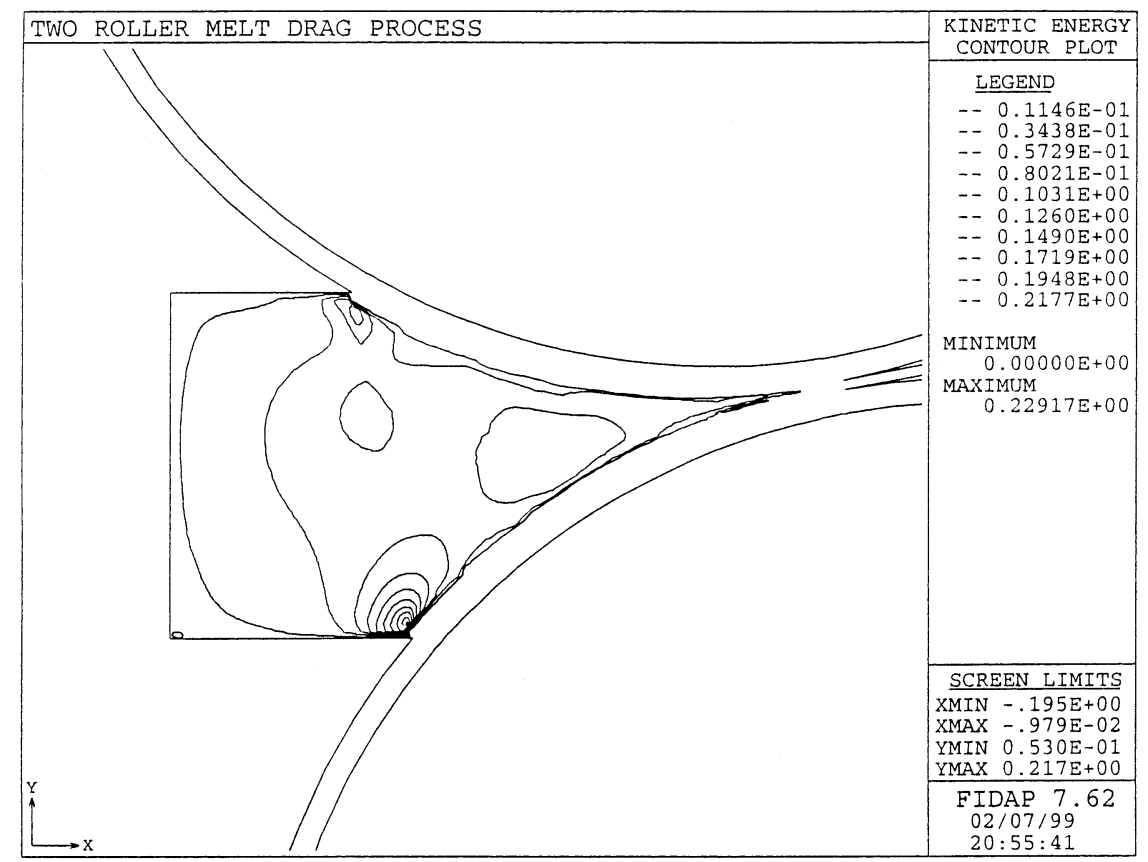

Fig. 7. Turbulent kinetic energy $\left(\mathrm{m}^{2} / \mathrm{s}^{2}\right)$ contours in the melt pool for two-roll melt drag thin strip casting of steel $\left(T_{\text {sup }}=60 \mathrm{~K}, V_{\text {roll }}=0.77 \mathrm{~m} / \mathrm{s}, U_{\text {in }}=0.05 \mathrm{~m} / \mathrm{s}, h_{\text {melt-roll }}=11000 \mathrm{~W} / \mathrm{m}^{2} \mathrm{~K}\right)$.

ic heat at an integration point is evaluated by computing the slope of the enthalpy-temperature curve based on the temperature at that point. The enthalpy-temperature curve for this model is shown in Fig. 4.

\section{Results and Discussion}

Figures 5 to 9 show the velocity vectors, temperature contours, turbulent kinetic energy contours, rate of dissipation of turbulent kinetic energy contours, and turbulent viscosity contours in the melt pool, respectively, for the case when inlet velocity is $0.15 \mathrm{~m} / \mathrm{s}$, roller velocity is $0.77 \mathrm{~m} / \mathrm{s}$, superheat in the liquid metal is $60 \mathrm{~K}$, and the melt-roll heat transfer coefficient is $11000 \mathrm{~W} / \mathrm{m}^{2} \mathrm{~K}$.

The velocity vector plot in the melt pool (Fig. 5) shows the metal, in the vicinity of the rolls, being dragged along the rolls at the same velocity. The excess metal, which could not be solidified, flows back with a relatively lesser velocity. Two recirculation loops in the flow of liquid metal can also be noticed from this vector plot.

Figure 6 shows the temperature contours in the melt pool and the rolls. The temperature contour of $1703 \mathrm{~K}$ (which is 


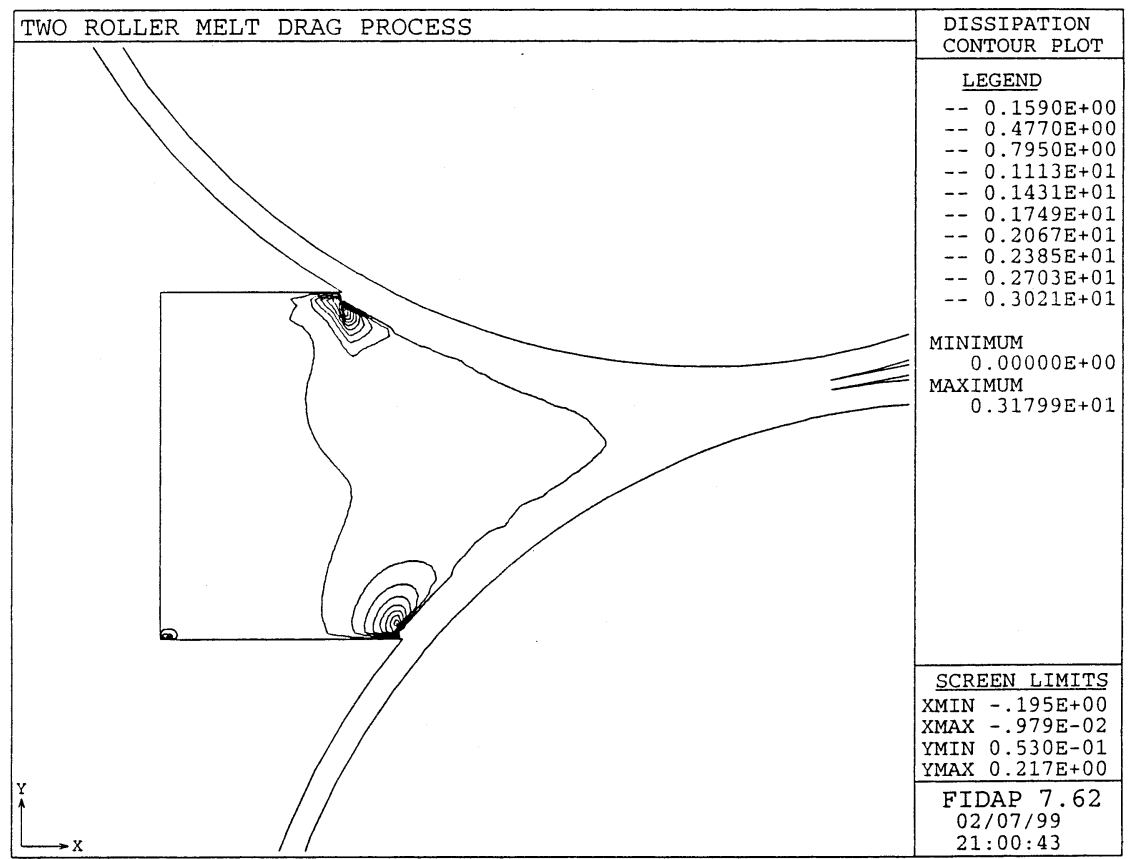

Fig. 8. Rate of dissipation of turbulent kinetic energy $\left(\mathrm{m}^{2} / \mathrm{s}^{2}\right)$ contours in the melt pool for two-roll melt drag thin strip casting of steel $\left(T_{\text {sup }}=60 \mathrm{~K}, V_{\text {roll }}=0.77 \mathrm{~m} / \mathrm{s}, U_{\text {in }}=0.05 \mathrm{~m} / \mathrm{s}, h_{\text {melt-roll }}=11000 \mathrm{~W} / \mathrm{m}^{2} \mathrm{~K}\right)$.

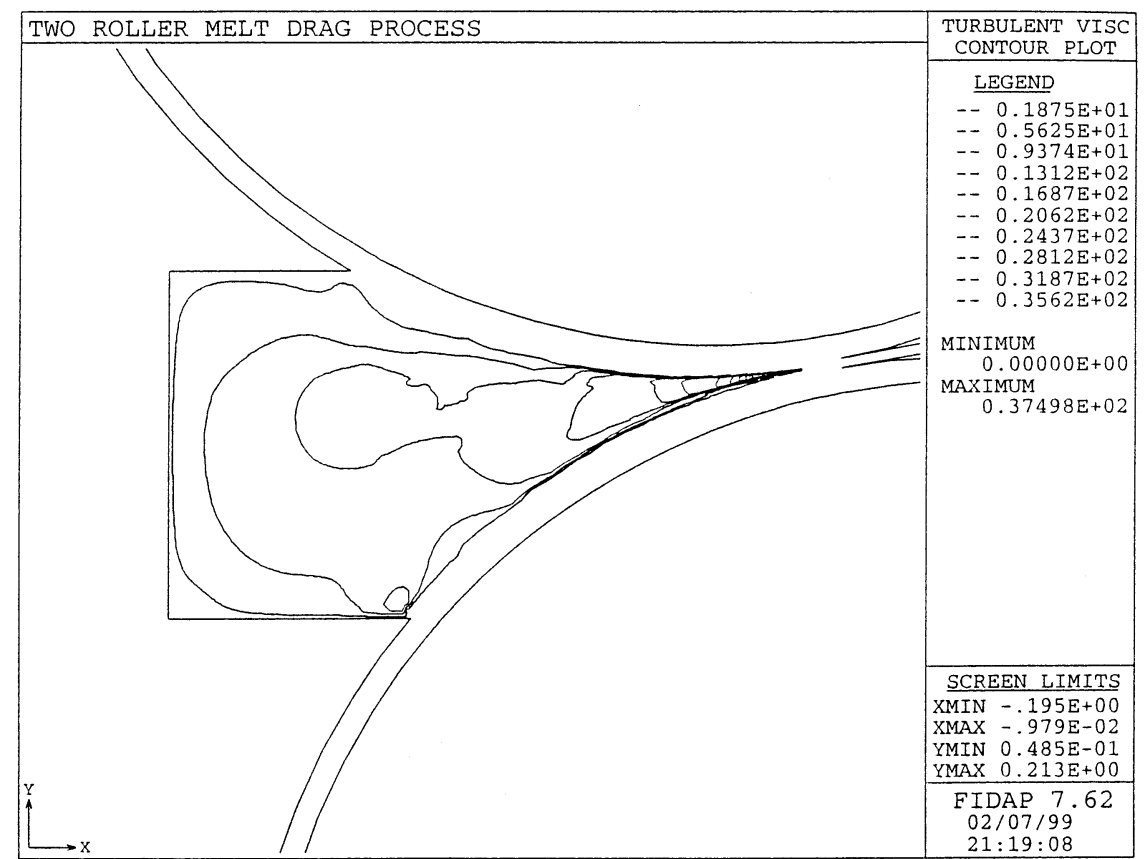

Fig. 9. Turbulent viscosity $(\mathrm{Pa} \cdot \mathrm{s})$ contours in the melt pool for two-roll melt drag thin strip casting of steel $\left(T_{\text {sup }}=60 \mathrm{~K}\right.$, $\left.V_{\text {roll }}=0.77 \mathrm{~m} / \mathrm{s}, U_{\text {in }}=0.05 \mathrm{~m} / \mathrm{s}, h_{\text {melt-roll }}=11000 \mathrm{~W} / \mathrm{m}^{2} \mathrm{~K}\right)$.

the mean of the liquidus and the solidus temperature) defines the solid-liquid interface in the melt pool.

The turbulent kinetic energy contour plot (Fig. 7) shows that the flow is more turbulent at the corners where liquid metal and rolls are in contact. It can be noticed that the turbulent kinetic energy is more near the upper roller. The rate of dissipation of turbulent kinetic energy contour plot (Fig. 8) shows that the dissipation of turbulence is highest at the corners where liquid metal and rolls are in contact. The turbulent viscosity contour plot (Fig. 9) shows that the highest turbulent viscosity observed in the melt pool is $35.62 \mathrm{~Pa} \cdot \mathrm{s}$, which is more than 7000 times of the molecular viscosity.

\subsection{Effect of the Position of the Inlet}

The inlet was moved from the bottom to near the top surface to see its effect on the turbulent flow profile. Figures $\mathbf{1 0}$ and $\mathbf{1 1}$ show the velocity vector plot and the turbulent kinetic energy contour plot for the new position of inlet at the operating conditions mentioned in the previous section, respectively. It can be noticed from the turbulent kinetic energy contour plot that this new position of the inlet results in a more symmetric flow. In this case, the highest turbulent 


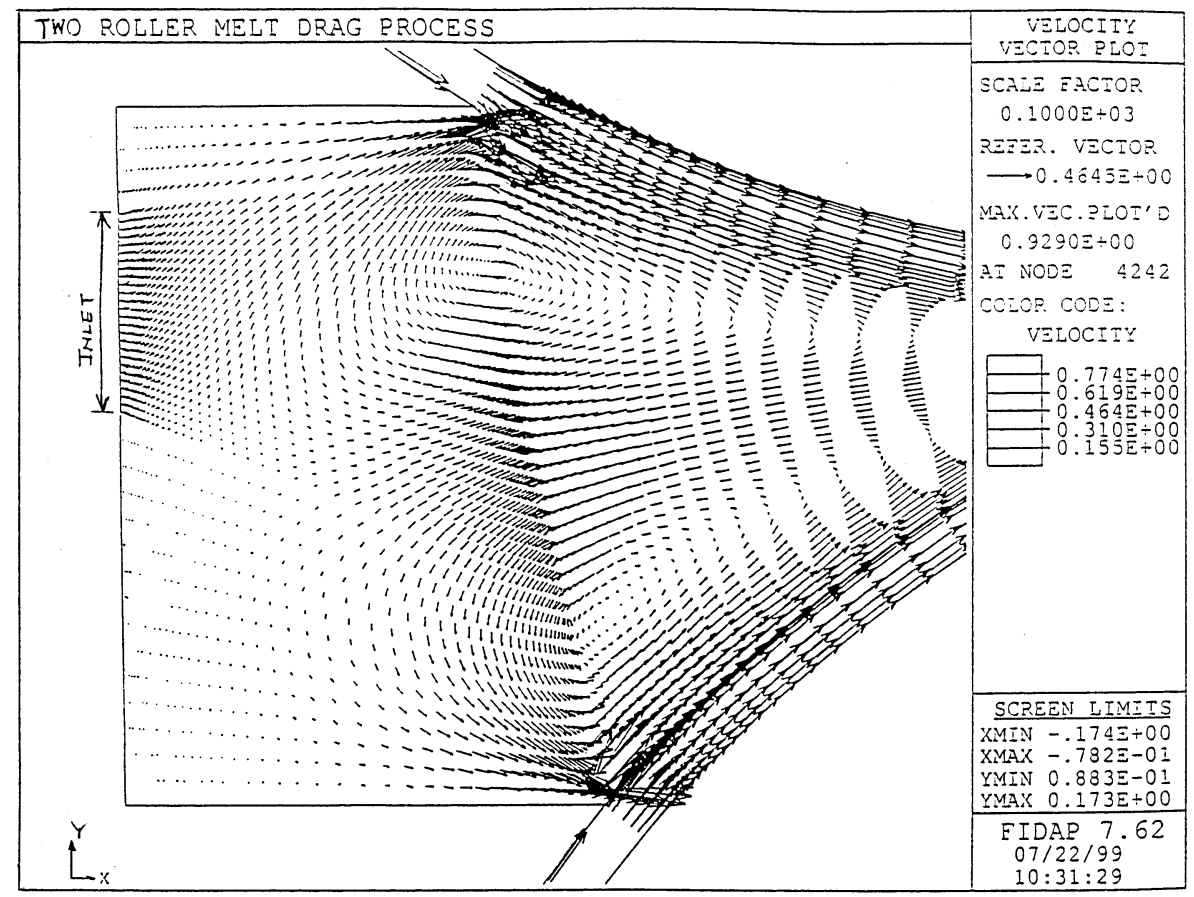

Fig. 10. Velocity $(\mathrm{m} / \mathrm{s})$ vectors in the melt pool when the inlet is near the top $\left(T_{\text {sup }}=60 \mathrm{~K}, V_{\text {roll }}=0.77 \mathrm{~m} / \mathrm{s}, U_{\text {in }}=0.05 \mathrm{~m} / \mathrm{s}\right.$, $\left.h_{\text {melt-roll }}=11000 \mathrm{~W} / \mathrm{m}^{2} \mathrm{~K}\right)$.

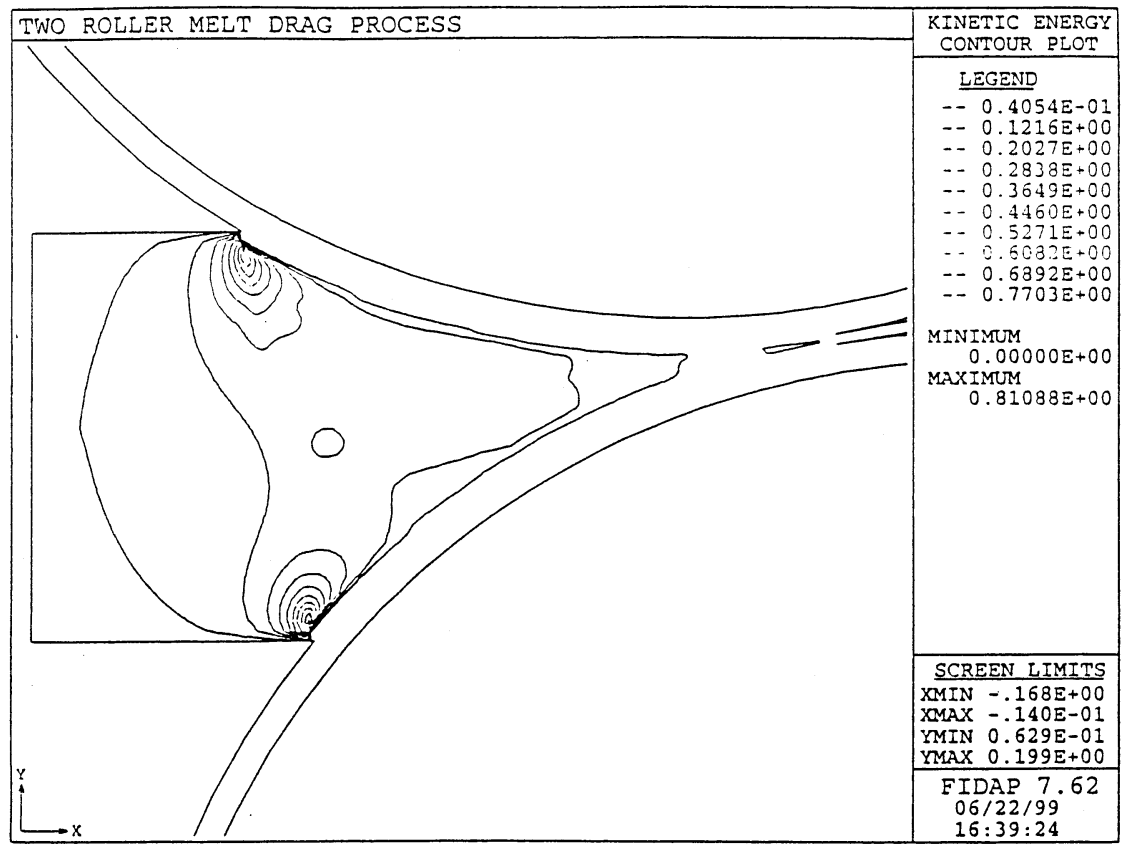

Fig. 11. Turbulent kinetic energy $\left(\mathrm{m}^{2} / \mathrm{s}^{2}\right)$ contour plot in the melt pool when the inlet is near the top $\left(T_{\text {sup }}=60 \mathrm{~K}, V_{\text {roll }}=\right.$ $0.77 \mathrm{~m} / \mathrm{s}, U_{\text {in }}=0.05 \mathrm{~m} / \mathrm{s}, h_{\text {melt-roll }}=11000 \mathrm{~W} / \mathrm{m}^{2} \mathrm{~K}$ ).

kinetic energy contour lies in between the two rolls, whereas in the earlier case the highest turbulent kinetic energy contour was near the upper roll. The thickness of the solidified shell was found to be the same for both the rolls in this case, whereas the earlier position of inlet results in higher shell thickness on the upper roll.

Process variables that affect the thickness of cast strip significantly were identified as:

(i) Roller speed

(ii) Melt-roll heat transfer coefficient

(iii) Melt superheat

\subsection{Effect of Roller Speed on Cast Strip Thickness}

Figure 12 shows the variation in strip thickness with the roller speed for different inlet velocities. It can be seen that as the inlet velocity increases the thickness of the solidified shell on the rolls also increases. Strip thickness is plotted as a function of the roller speed for three values of inlet velocities. An inlet velocity of $0.05 \mathrm{~m} / \mathrm{s}$ results in the thinnest strips whereas a inlet velocity of $0.15 \mathrm{~m} / \mathrm{s}$ results in the thickest strips.

The roll separation ' $t$ ' is calculated according to the 


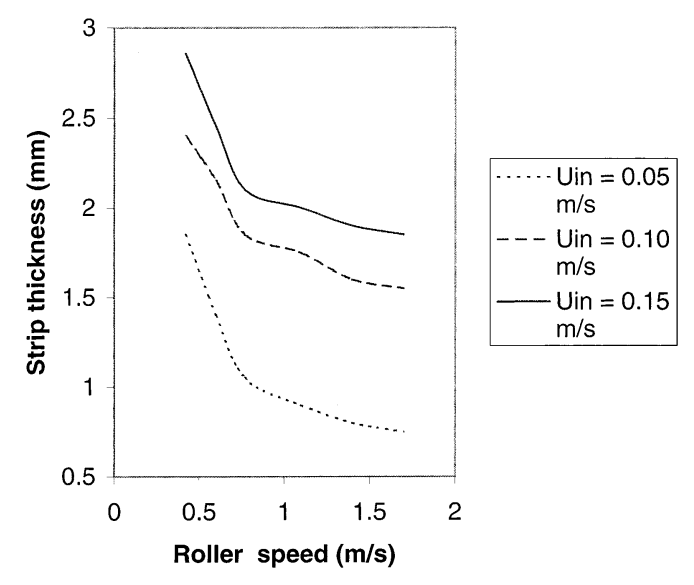

Fig. 12. Strip thickness as a function of roller speed in two-roll melt drag thin strip casting of steel for different casting speeds $\left(T_{\text {sup }}=60 \mathrm{~K}, h_{\text {melt-roll }}=11000 \mathrm{~W} / \mathrm{m}^{2} \mathrm{~K}\right)$.

equation:

$$
U_{\text {in }} \cdot d_{\text {in }}=V_{\text {roll }} \cdot t
$$

As the inlet velocity increase, the roll separation is increased accordingly to satisfy the above equation. As roll separation increases, the depth of melt pool also increases to ensure that the contact length remains same for both the rolls. This results in a higher contact length of molten metal and rolls, which results in a thicker solidified shell on the rolls.

It can be seen that the strip thickness decreases with increase in roller speed. This is because, at higher casting speed contact time of melt with roller is less, hence the time provided for solidification of liquid metal is also less, which results in thinner strips. From Fig. 12, it also evident that the growth rate for low roller speed is higher than that for high roller speeds. This result was also observed by Miyazawa et al. ${ }^{9)}$ in a study, which concluded that the contact time between metal and roll is the most important parameter that governs the strip thickness.

\subsection{Effect of Melt-roll Heat Transfer Coefficient on Cast Strip Thickness}

Melt-roll heat transfer coefficient governs the rate of heat transfer from melt pool to roller. Figure 13 shows the variation in strip thickness with melt-roll heat transfer coefficient at inlet velocity equal to $0.15 \mathrm{~m} / \mathrm{s}$, melt superheat equal to $60 \mathrm{~K}$, and roll velocity equal to $0.77 \mathrm{~m} / \mathrm{s}$. It can be seen from the figure that as the value of melt-roll heat transfer coefficient increases, the thickness of cast strip also increases. In the present investigation, melt-roll heat transfer coefficient was varied from $9000 \mathrm{~W} / \mathrm{m}^{2} \mathrm{~K}$ to $20000 \mathrm{~W} /$ $\mathrm{m}^{2} \mathrm{~K}$ to see its effect on strip thickness. Strip thickness increased from $0.86 \mathrm{~mm}$ to $1.2 \mathrm{~mm}$. In this range and at operating conditions mentioned before, the strip thickness can be represented by the following equation:

$$
\begin{aligned}
\text { Strip thickness }(\mathrm{mm})= & 0.0228 \cdot(\text { Melt-roll heat transfer } \\
& \text { coeff. } \left.\left(\mathrm{kW} / \mathrm{m}^{2} \mathrm{~K}\right)\right)^{0.4004}
\end{aligned}
$$

\subsection{Effect of Melt Superheat on Cast Strip Thickness}

Figure 14 shows the variation in strip thickness with the melt superheat at inlet velocity equal to $0.15 \mathrm{~m} / \mathrm{s}$, roll speed

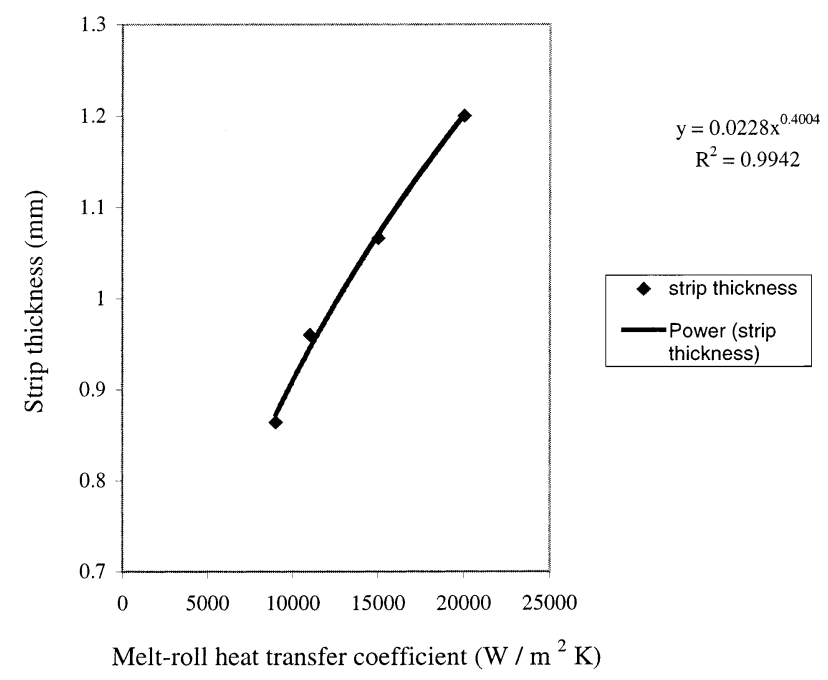

Fig. 13. Strip thickness as a function of melt-roll heat transfer conefficient in two-roll melt drag thin strip casting of steel $\left(T_{\text {Sup }}=60 \mathrm{~K} . V_{\text {roll }}=0.77 \mathrm{~m} / \mathrm{s}, U_{\text {in }}=0.05 \mathrm{~m} / \mathrm{s}\right)$.

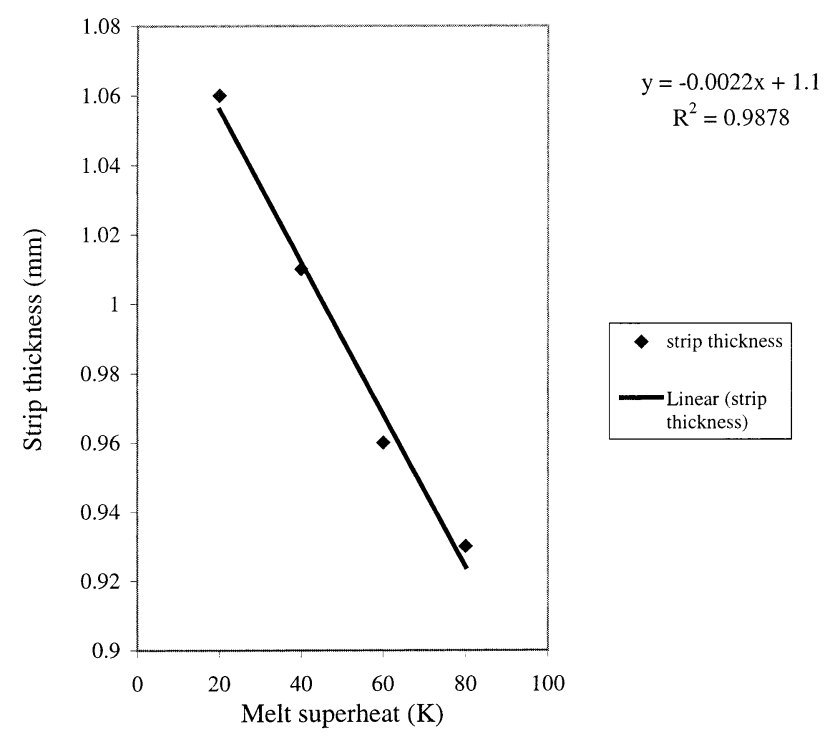

Fig. 14. Strip thickness as a function of melt superheat in tworoll melt drag thin strip casting of steel $\left(V_{\text {roll }}=0.77 \mathrm{~m} / \mathrm{s}\right.$, $U_{\text {in }}=0.05 \mathrm{~m} / \mathrm{s}, h_{\text {mell-roll }}=11000 \mathrm{~W} / \mathrm{m}^{2} \mathrm{~K}$ ).

equal to $0.77 \mathrm{~m} / \mathrm{s}$, and melt-roll heat transfer coefficient equal to $11000 \mathrm{~W} / \mathrm{m}^{2} \mathrm{~K}$. Larger amount of heat is to be removed through the solidifying strip in case of liquid steel with higher superheat. This, in turn reduces the solidification rate. It can be seen in Fig. 14 that, increase in superheat of liquid steel reduces the solidified thickness of the shell. In the present investigation, melt superheat was varied from 20 to $80 \mathrm{~K}$ to see the sensitivity of strip thickness with respect to melt superheat. Strip thickness reduced from 1.06 to $0.93 \mathrm{~mm}$. The effect of superheat of strip thickness does not seem to be significant because the major part of heat came from the release of latent heat of fusion and not from the melt superheat. Sensible heat due to superheat is very small compared to the latent heat of fusion. In this range and at operating conditions mentioned before, the strip thickness can be represented by the following equation:

Strip thickness $(\mathrm{mm})=-0.0022 \cdot($ Melt superheat $(K))+1.1$ 


\section{Conclusion}

A two-dimensional mathematical model was developed to simulate turbulent fluid flow, heat transfer, and solidification in two-roll melt drag process. Relationships between various operating parameters like roller speed, melt-roll heat transfer coefficient, and melt superheat and cast strip thickness were obtained from this model. Roller speed and melt-roll heat transfer coefficient were found to be the main parameters affecting the cast strip thickness while melt superheat showed little effect. The position of inlet was changed to investigate its effect on the turbulent flow profile and it was found that when the inlet is close to upper surface of the melt pool it gives a more symmetric turbulent flow. These observations show the applicability of the present mathematical model as a design tool for the two-roll melt drag casters.

\section{Acknowledgement}

This research was supported by a grant from National Science Foundation under the GOALIE program from the Division of Manufacturing and Industrial Innovation.

\section{Nomenclature}

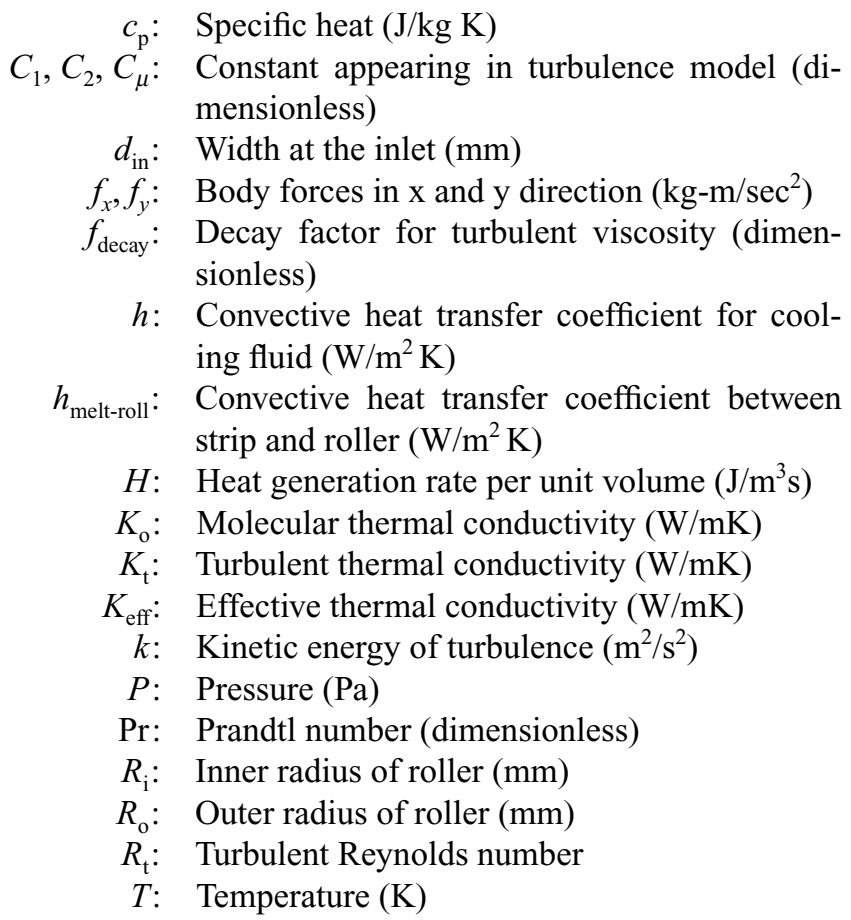

$T_{\text {in }}$ : Inlet temperature of molten steel (K)

$T_{\text {liq }}$ : Liquidus temperature of molten steel $(\mathrm{K})$

$T_{\text {sol }}$ : Solidus temperature of molten steel $(\mathrm{K})$

$T_{\text {sup }}:$ Superheat in molten steel (K)

$t$ : Roll separation (mm)

$U: \quad x$ (horizontal) component of velocity $(\mathrm{m} / \mathrm{s})$

$U_{\text {in }}:$ Inlet velocity $(\mathrm{m} / \mathrm{s})$

$U_{\mathrm{n}}$ : Normal component of velocity $(\mathrm{m} / \mathrm{s})$

$U_{\mathrm{t}}$ : Tangential component of velocity $(\mathrm{m} / \mathrm{s})$

$U_{\text {wall }}: \quad x$ component of the velocity at the walls $(\mathrm{m} / \mathrm{s})$

$V: \quad y$ (vertical) component of velocity $(\mathrm{m} / \mathrm{s})$

$V_{\text {cast }}:$ Casting speed $(\mathrm{m} / \mathrm{s})$

$V_{\text {wall }}: \quad y$ component of the velocity at the walls $(\mathrm{m} / \mathrm{s})$

$x$ : Cartesian coordinate in the horizontal direction

$y$ : Castresian coordinate in the vertical direction

$\mu_{\mathrm{o}}$ : Molecular viscosity $(\mathrm{Pa} \cdot \mathrm{sec})$

$\mu_{\mathrm{t}}$ : Turbulent viscosity $(\mathrm{Pa} \cdot \mathrm{sec})$

$\mu_{\text {eff }}:$ Effective viscosity $(\mathrm{Pa} \cdot \mathrm{sec})$

$\varepsilon$ : Dissipation rate of kinetic energy $\left(\mathrm{m}^{2} / \mathrm{s}^{3}\right)$

$\varepsilon_{i j}$ : Shear rate (deformation) tensor

$\lambda$ : Fraction of solid

$\rho$ : Density $\left(\mathrm{kg} / \mathrm{m}^{3}\right)$

$\sigma_{k}$ and $\sigma_{\varepsilon}:$ Constants appearing in turbulence model

$\tau_{\mathrm{ij}}:$ Deviatoric part of the stress tensor

\section{REFERENCES}

1) Shailesh Gupta: Mathematical modeling of thin strip casting processes., M. S. thesis, department of Materials Science and Engineering, Ohio State University, Columbus, Ohio, (1998).

2) B. E. Launder and D. B. Spalding: Computational Methods in Applied Mechanics and Engineering, 3 (1974), 269.

3) FIDAP theory manual: Fluid Dynamics International Inc., Evanston, IL, (1993).

4) H. Yamane, M.Yukomoto, S. Miyake, and M.Ozawa: Proc. 10th PTD Conf., ISS, Warrendale, PA, (1992), 343.

5) B. Q. Li: J. Met., 47 (1995), 13

6) A. Kasma, S. Mizoguchi, K. Miyazawa, M. Ito, and T. Sugai: Proc. Near Net Shape Casting Processes, TMS, Warrendale, PA, (1987), 849.

7) K. Miyazawa, T. Choh and M. Inoye: Trans. Jpn. Inst. Met., 24 (1983), 696.

8) T. Yamauchi, T. Nakanori, M. Hasegawa, T. Yabuki, and N. Ohnishi: Trans. Iron Steel Jpn., 28 (1988), 23.

9) K. Miyazawa, T. Mizoguchi, N. Nakamura, and T. Ohashi: Casting of Near Net Products, ed. by Y. Sahai, J. E. Battles, R. S. Carbonara, and C. E. Mobley, TMS, Warrendale, PA, (1988), 629. 